\title{
Reliability and validity of the Spanish version of the 10-item Connor-Davidson Resilience Scale (10-item CD-RISC) in young adults
}

\author{
Blanca Notario-Pacheco ${ }^{1}$, Montserrat Solera-Martínez ${ }^{1}$, María D Serrano-Parra ${ }^{2}$, Raquel Bartolomé-Gutiérrez ${ }^{3}$, \\ Javier García-Campayo ${ }^{4}$ and Vicente Martínez-Vizcaíno ${ }^{1 *}$
}

\begin{abstract}
Background: The 10-item Connor-Davidson Resilience Scale (10-item CD-RISC) is an instrument for measuring resilience that has shown good psychometric properties in its original version in English. The aim of this study was to evaluate the validity and reliability of the Spanish version of the 10-item CD-RISC in young adults and to verify whether it is structured in a single dimension as in the original English version.

Findings: Cross-sectional observational study including 681 university students ranging in age from 18 to 30 years. The number of latent factors in the 10 items of the scale was analyzed by exploratory factor analysis. Confirmatory factor analysis was used to verify whether a single factor underlies the 10 items of the scale as in the original version in English. The convergent validity was analyzed by testing whether the mean of the scores of the mental component of SF-12 (MCS) and the quality of sleep as measured with the Pittsburgh Sleep Index (PSQI) were higher in subjects with better levels of resilience. The internal consistency of the 10-item CD-RISC was estimated using the Cronbach $\alpha$ test and test-retest reliability was estimated with the intraclass correlation coefficient. The Cronbach $\alpha$ coefficient was 0.85 and the test-retest intraclass correlation coefficient was 0.71 . The mean MCS score and the level of quality of sleep in both men and women were significantly worse in subjects with lower resilience scores.

Conclusions: The Spanish version of the 10-item CD-RISC showed good psychometric properties in young adults and thus can be used as a reliable and valid instrument for measuring resilience. Our study confirmed that a single factor underlies the resilience construct, as was the case of the original scale in English.
\end{abstract}

Keywords: Resilience, 10-item CD-RISC, Young adults, Reliability, Validity, Questionnaire

\section{Background}

Resilience has been defined as a protective factor against mental problems and as a dynamic process of adaptation to changes in life circumstances $[1,2]$. Various instruments are available for measuring resilience $[3,4]$. The Connor-Davidson Resilience Scale (CD-RISC) [5] is a self-administered scale of 25 items that exhibits excellent psychometric properties in young adults [6,7]. Originally structured in five dimensions, the factor structure of the CD-RISC has revealed certain limitations in the multidimensional concept proposed. For

\footnotetext{
* Correspondence: Vicente.martinez@uclm.es

'Social and Health Care Research Center, University of Castilla-La Mancha, Cuenca, Spain

Full list of author information is available at the end of the article
}

that reason a new 10-item version was developed, which resulted in a stable scale with excellent psychometric properties [6].

As far as the authors know, the psychometric properties of the Spanish version of the 10-item CD-RISC have not been evaluated. Therefore, this study aimed to evaluate the validity and reliability of the Spanish version of the 10item CD-RISC in young adults of Cuenca, Spain, in addition to verifying the single dimension factor structure.

\section{Findings}

Study design and population

Cross-sectional, observational study in which were invited to participate a total of 770 first-year university students, age 18 to 30 years, of the Castile-La Mancha

\section{Biomed Central}


University in Cuenca campus, Spain. Six hundred eighty-three $(88.7 \%)$ students participated in the study and 681 correctly completed the questionnaires. Students who refused to participate in the study were similar in mean age and sex distribution to participants. We were unable to ask for the reason for their refusal due to compulsory indications in this sense of Clinical Research Ethics Committee.

The study protocol was approved by the Clinical Research Ethics Committee of Hospital Virgen de la Luz of Cuenca. All the subjects were asked to sign the informed consent to participate in the study after receiving oral and written information about the study objectives and procedures.

\section{Measurement variables and instruments}

All the subjects were administered a battery of tests to determine, in addition to the sociodemographic variables:

\section{- Resilience}

This was evaluated using the 10 -item CD-RISC $[6,8]$, a self-administered questionnaire of 10 items designed as a Likert type additive scale with five response options (0 = never; 4 = almost always), which had a single dimension in the original version. The final score on the questionnaire was the sum of the responses obtained on each item (range 0-40) and the highest scores indicated the highest level of resilience. In order to define the final version, the version of the scale translated into Spanish provided by the authors of the original scale and was adapted with minimal changes [9].

\section{- Mental health}

The Mental Component Summary (MCS) of the SF-12 quality of life questionnaire, adapted and validated in Castilian Spanish was used [10].

\section{-Quality of sleep}

The Pittsburgh Sleep Quality Index (PSQI) [11] is a simple, short self-administered questionnaire, consisting of 19 questions for the patient and 5 more questions for the partner, and structured in seven dimensions. Each dimension was scored from 0 to 3 and the final score obtained was 0 to 21 . The scale is negative and the highest score corresponds to the worst quality of sleep. Approved Spanish version was used [12].

\section{Questionnaire administration strategy}

Students were convened for meetings in the classrooms of the respective centers, where the study objectives and procedures were explained. After the presentation, all the students who signed the informed consent were given the questionnaire to complete. Three investigators were in the classroom while students completed the questionnaires to avoid contamination between the responses of each one.

\section{Statistical analysis and validation process Construct validity}

Principal components analysis (PCA) was used to analyze a number of factors underlying the scale. The Bartlett sphericity test and KMO index were used to assess the suitability of the factor solution. An eigenvalue of 1 was used as a criterion for factor extraction. A sedimentation graph was used to analyze the suitability of the number of factors extracted.

The suitability of a single factor model underlying 10item CD-RISC was analyzed by confirmatory factor analysis (CFA) with IBM SPSS Amos 19 software. Because of sex differences in resilience have been described [13], we tested if the factor structure of resilience construct was similar for both men and women, and analyses were performed for each sex and Chi-squared tests were used to examine differences in factors loadings between the sexes. As the sample sizes were relatively large $(n=681)$, the goodness of fit of the hypothetical models to the sample data was assessed with the $\mathrm{Hu}$ and Bentler criteria [14].

To test the factor structure of the 10-item CD-RISC, we splitted the sample into two subsamples randomly and conducted PCA and CFA using this two sub-samples respectively.

\section{Convergent validity}

The total 10-item CD-RISC score was categorized as: low resilience (first quartile), moderate resilience (second and third quartiles) and high resilience (fourth quartile). Given that the highest levels of resilience are associated with better mental health conditions [15] and that certain mental problems like anxiety and depression are associated with sleep disorders and less resilience $[11,16]$, the convergent validity of the scale was analyzed, by gender, by ANCOVA models using MCS mean and PSQI mean as dependent variables, 10-item CDRISC categories as fixed factors, and age as covariate. Effect sizes ' $d$ ' were calculated employing the estimated marginal means and were interpreted as small $(0.20$ $0.50)$, moderate $(0.51-0.80)$ or large $(>0.80)$ [17].

\section{Reliability}

The internal consistency of the scale was evaluated by calculating Cronbach's alpha coefficient. Test-retest reliability was examined in a subsample of 95 students selected randomly from all the sample subjects who completed this questionnaire two times, once when they were convened to participate in the study and the second time two weeks later. The tests-retest intraclass correlation coefficient was used in the reproducibility analysis of the 10-item CD-RISC.

Except for CFA, analyses were performed with IBM SPSS Statistics 19 software [18].

\section{Results}

The final sample included 681 first-year university students, age range 18 to 30 years $($ mean $=20.08 ; S D=$ 
4.12). Off these, 506 (73.86\%) were women, percentage in accordance with the sex ratio in the University Campus of Cuenca, Spain. The mean score of 10-item CDRISC for the total sample was 27.41 ( $S D=6.36)$; students over 25 years showed scores significantly lower $(27.06$; $\mathrm{SD}=6.36)$ than students under 25 years $(29.86$; $\mathrm{SD}=6.52), \mathrm{p}<0.05$. Also, the mean score of 10 -item CD-RISC was significantly higher in men (29.47; SD = $5.80)$ than in women $(26.46 ; \mathrm{SD}=6.43) \mathrm{p}<0.001$.

None of the participants obtained a total score of 0 on the scale (floor effect), and only $2.3 \%$ of subjects obtained the maximum score (ceiling effect).

\section{Construct validity}

The factor solution was adequate. The result of the KMO test was 0.90 and the Barlett sphericity was significant $\left(\chi^{2}=2074.7 ; \mathrm{gl}=45 ; \mathrm{p}=0.001\right)$. Only one factor showed an eigenvalue greater than 1 . This factor explained $44.1 \%$ of the variance. The saturation of each item on the PCA is presented in Table 1. The sedimentation graph showed a single suitable factor solution (Figure 1).

\section{Confirmatory factor analysis}

(Figure 2: $\chi^{2}=159.4, \mathrm{df}=35, \mathrm{p}=0.001$; CFI = 0.939; and SRMR $=0.041$ ). The single factor model proposed for the CFA of the 10-item CD-RISC, by sex, is shown in Figure 3. The model displayed a good fit by sex and the factor loading showed no differences between men and women (Figure 3: $\chi^{2} \mathrm{diff}=9.4, \mathrm{df}=9, \mathrm{p}=0.40$ ).

We separated randomly the sample into two groups, and the PCA and CFA results did not show significant differences between groups.

\section{Convergent validity}

The differences in the mean score of the MCS and in the mean score of the PSQI by resilience category, controlling for age, by gender, are shown in Table 2. The quality of sleep in both men and women was

Table 1 Factor structure of the 10-item CD-RISC

\begin{tabular}{lc}
\hline \multicolumn{1}{c}{ Items } & Saturation \\
\hline 1. Able to adapt to change & 0.843 \\
2. Can deal with whatever comes & 0.834 \\
3. Tries to see humorous side of problems & 0.836 \\
4. Coping with stress can strengthen me & 0.838 \\
5. Tends to bounce back after illness or hardship & 0.849 \\
6. Can achieve goals despite obstacles & 0.833 \\
7. Can stay focused under pressure & 0.845 \\
8. Not easily discouraged by failure & 0.851 \\
9. Thinks of self as strong person & 0.828 \\
10. Can handle unpleasant feelings & 0.843 \\
\hline
\end{tabular}

Cronbach $\alpha=0.854$

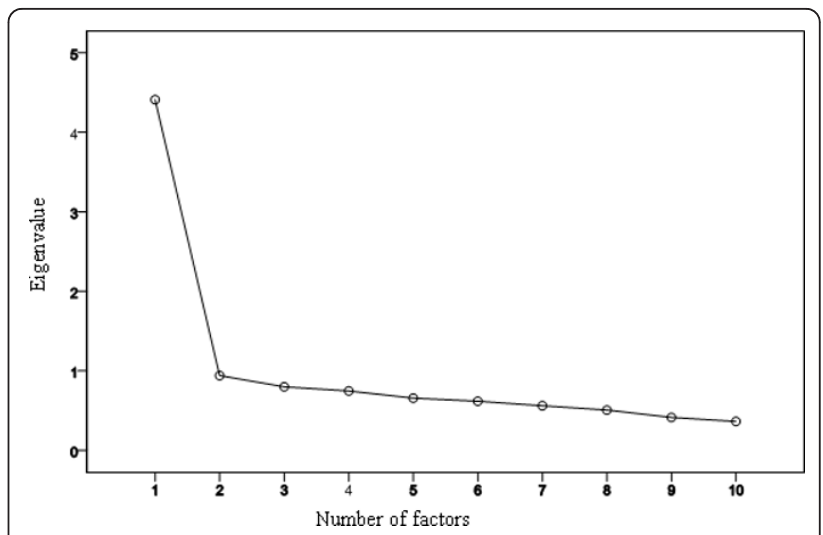

Figure 1 Sedimentation graph of factor components of 10item CD-RISC.

significantly worse in subjects with lower resilience scores. On the other hand, the score on the MCS was also significantly lower in both men and women in the lowest resilience category.

\section{Reliability}

The mean correlation between items was 0.37 , the lowest value being 0.20 and the highest value being 0.57 .

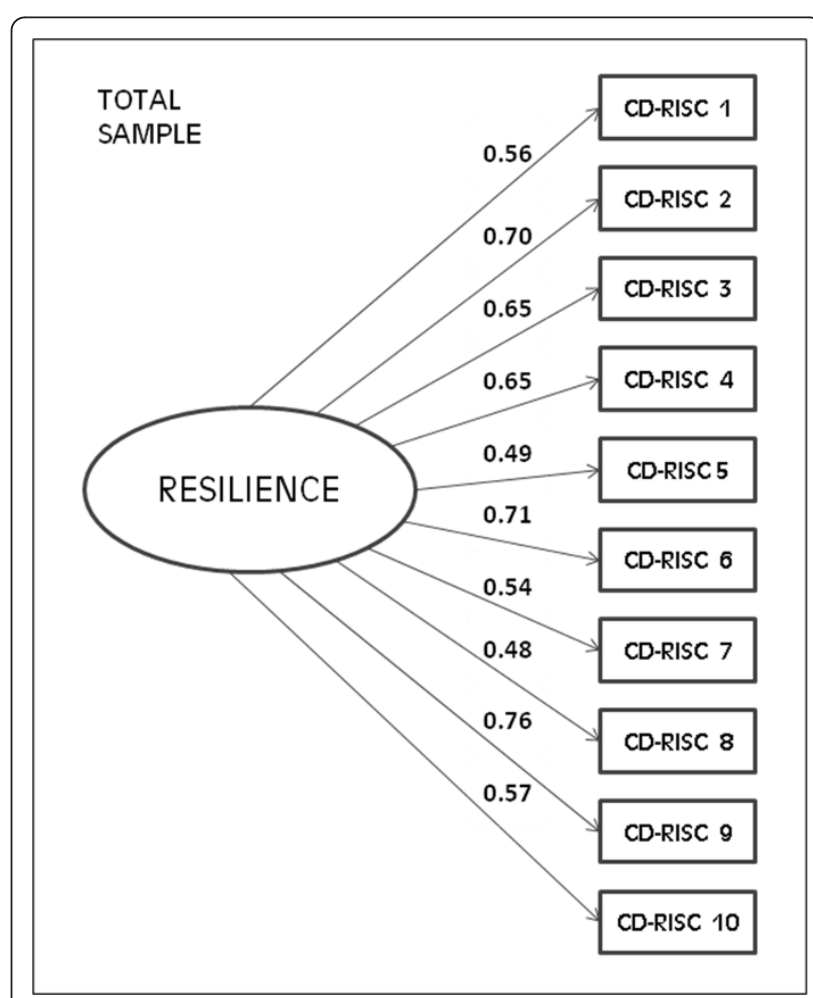

Figure 2 Factor loading and goodness-of-fit indexes of onefactor model for the 10-items CD-RISC factor structure. Total sample: $\mathrm{n}=681 ; \chi^{2}=159.4, \mathrm{df}=35, \mathrm{p}=0.001, \mathrm{CFI}=0.94$ and $\operatorname{SRMR}=0.041$. 


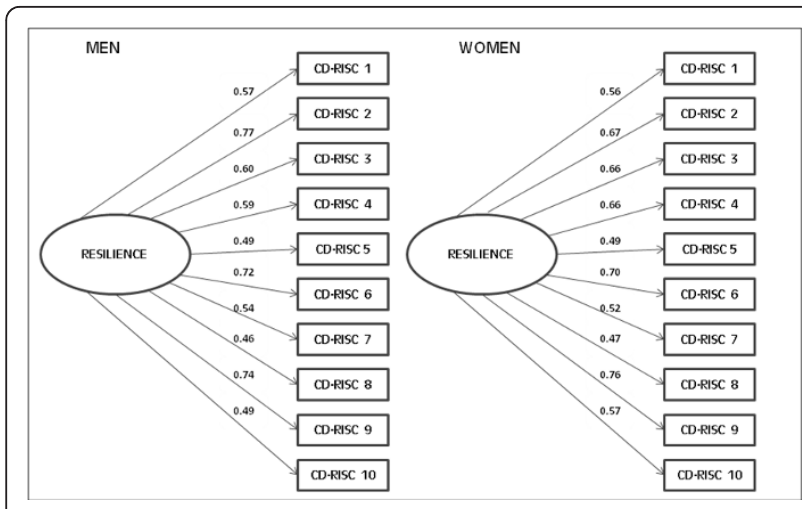

Figure 3 Factor loading and goodness-of-fit indexes for our single-factor model for the CD-RISC-10 factor structure, by sex. Men: $\mathrm{n}=175 ; \chi^{2}=135.8, \mathrm{df}=35, \mathrm{p}=0.001, \mathrm{CFI}=0.82$ and SRMR $=0.073$. Women: $\mathrm{n}=506 ; \chi^{2}=106.4, \mathrm{df}=35, \mathrm{p}=0.001, \mathrm{CFI}=0.95$ and $\mathrm{SRMR}=0.040$.

The range of values of the item-total scale score correlation was 0.45 to 0.69 . Cronbach's alpha was 0.854 and did not increase after eliminating any of the items. The intraclass correlation coefficient between the total score on the first 10-item CD-RISC questionnaire administered and the total score on the scale two weeks later was $0.711(95 \% \mathrm{CI}=0.596-0.798)$; the Spearman correlation coefficient was 0.73 (Table 3 ).

\section{Conclusions}

The findings of our study confirmed that the Spanish version of the 10-item CD-RISC show good
Table 3 Correlation of the test-retest reliability analysis

\begin{tabular}{lccc}
\hline & Test & Test & Retest \\
\hline $\mathrm{N}$ & 681 & 95 & 95 \\
Mean (SD) & $27.41(6.36)$ & $27.03(5.98)$ & $27.74(5.08)$ \\
Mean CD-RISC & $23 / 32$ & $22 / 31$ & $24 / 32$ \\
$\mathrm{P}_{25} / 75$ & & & \\
Cronbach's alpha & 0.854 & 0.831 & 0.807 \\
Spearman correlation & & & $0.732^{*}$ \\
\hline
\end{tabular}

${ }^{*} p<0.001$

psychometric properties and a high level of reliability and validity in young adults. The findings also confirmed a single dimension underlying the 10 items of the scale.

The reliability of the Spanish version of the 10-item CD-RISC was similar to that of the original version (Cronbach's $\alpha$ of the original version $=0.85$ and of the Spanish version $=0.85$ ), and the weights in factor analysis were within the range of $0.48-0.76$ on our scale and within the range of $0.44-0.74$ in the original.

The factor structure of the CD-RISC is debated [7,19-21], and no consensus exists regarding the number of factors composing this scale. It has been observed [22] that eliminating the items that were highly correlated resulted in a unidimensional final 10 -item scale that was easier to complete and provided essentially the same information as the 25 -item version [6]. Our data confirm that a single factor underlies the resilience construct, as in the original 10-item CD-RISC version, and suggests that the 10-item CD-RISC is an unidimensional measure of resilience.

Table 2 Mean score of the SF-12 mental component and Pittsburgh sleep quality index by resilience category, controlling for age, by sex

\begin{tabular}{|c|c|c|c|c|c|c|c|}
\hline & & $\begin{array}{c}\text { PSQI } \\
\text { Mean (SD) }\end{array}$ & & & & & \\
\hline \multirow[t]{2}{*}{ 10-item CD-RISC } & $\begin{array}{l}\text { Low Resilience } \\
\text { (Percentile <25) }\end{array}$ & $\begin{array}{l}\text { Moderate Resilience } \\
\text { (Percentile 25-75) }\end{array}$ & $\begin{array}{l}\text { High Resilience } \\
\text { (Percentile >75) }\end{array}$ & $p$ & & Effect size & \\
\hline & & & & & $1-2$ & $1-3$ & $2-3$ \\
\hline Men & $\begin{array}{c}7.00(3.31) \\
n=22\end{array}$ & $\begin{array}{c}5.58(2.56) \\
n=101\end{array}$ & $\begin{array}{c}5.40(3.16) \\
n=55\end{array}$ & 0.029 & 0.48 & 0.49 & 0.06 \\
\hline Women & $\begin{array}{c}6.99(3.33) \\
n=167\end{array}$ & $\begin{array}{c}6.22(2.95) \\
n=245\end{array}$ & $\begin{array}{c}5.86(2.89) \\
n=90\end{array}$ & 0.003 & 0.24 & 0.36 & 0.12 \\
\hline \multirow[t]{2}{*}{ Total } & $\begin{array}{c}6.99(3.32) \\
n=189\end{array}$ & $\begin{array}{c}6.03(2.85) \\
n=346\end{array}$ & $\begin{array}{c}5.69(2.99) \\
n=145\end{array}$ & $<0.001$ & 0.31 & 0.41 & 0.12 \\
\hline & & $\begin{array}{c}\text { MCS } \\
\text { Mean (SD) }\end{array}$ & & & & & \\
\hline \multirow[t]{2}{*}{ 10-item CD-RISC } & $\begin{array}{l}\text { Low Resilience } \\
\text { (Percentile <25) }\end{array}$ & $\begin{array}{c}\text { Moderate Resilience } \\
\text { (Percentile 25-75) }\end{array}$ & $\begin{array}{l}\text { High Resilience } \\
\text { (Percentile >75) }\end{array}$ & $\mathrm{p}$ & & Effect size & \\
\hline & & & & & $1-2$ & $1-3$ & $2-3$ \\
\hline Men & $\begin{array}{c}39.87(6.15) \\
n=22\end{array}$ & $\begin{array}{c}41.92(5.07) \\
n=100\end{array}$ & $\begin{array}{c}43.06(5.78) \\
n=53\end{array}$ & 0.013 & 0.36 & 0.53 & 0.21 \\
\hline Women & $\begin{array}{c}37.37(6.14) \\
n=166\end{array}$ & $\begin{array}{c}38.89(6.41) \\
n=240\end{array}$ & $\begin{array}{c}42.00(5.57) \\
n=89\end{array}$ & 0.001 & 0.24 & 0.79 & 0.52 \\
\hline Total & $\begin{array}{c}37.66(6.18) \\
n=188\end{array}$ & $\begin{array}{c}39.78(6.20) \\
n=340\end{array}$ & $\begin{array}{c}42.40(5.65) \\
n=142\end{array}$ & $<0.001$ & 0.34 & 0.80 & 0.44 \\
\hline
\end{tabular}


Sleep disturbances coincide frequently with mental and/or physical disorders [23,16]. Likewise, different studies made in adolescents have shown that subjects with a high level of resilience are less likely to present mental disorders, interpersonal conflicts, behavior disorders and poor academic performance $[24,25]$. A recent study has found that the variation in the 5HTTPR gene is associated with individual differences in resilience [26], which could predict the appearance of mental health problems. Our results support the convergent validity of the scale because they showed that both the quality of sleep and the mean score of the MCS worse in both men and women with lower resilience scores. Other studies have commonly used posttraumatic stress scales as measures of convergent validation [5,6]; in our study was not possible to use these kind of measures because of the low lifetime prevalence of severe stressful events at the age of our sample.

Nonetheless, these results should be interpreted with caution given the limitations of this study. As a crosssectional study, the results do not establish predictive validity between the levels of resilience and the MCS and the PSQI. Moreover, the sample studied included only university student, so our results certainly cannot be extrapolated to the general population. However, among the strengths of our study it should be noted that this is the first validation study of the 10-item CDRISC in Castilian Spanish, and that this short and simple instrument requires little time to complete and is thus efficiently administered. For that reason, it may be a suitable instrument for clinical use and in community studies.

\section{Acknowledgements \\ This study was funded mainly by la Fundación para la Investigación Sanitaria en Castilla-La Mancha (FISCAM) (Ref.-AN/2008/31). Additional funding was obtained from the Instituto de Salud Carlos III, Red de Investigación en Actividades Preventivas y de Promoción de Salud (Ref.- RD06/0018/0038). We thank all people that have participated in this research. \\ Author details \\ ${ }^{1}$ Social and Health Care Research Center, University of Castilla-La Mancha, Cuenca, Spain. ${ }^{2}$ Faculty of Nursing, University of Castilla-La Mancha, Cuenca, Spain. ${ }^{3}$ Faculty of Nursing, University of Castilla-La Mancha, Albacete, Spain. ${ }^{4}$ Miguel Servet Hospital. University of Zaragoza. Aragon's Institute of Health Sciences, Spain.}

\section{Authors' contributions}

BNP conceived the study design and contributed to collect the data and to redact the manuscript. MSM conducted the statistical analysis. MDSP, RBG and JGC contributed to draft the manuscript. VMV is the main researcher of the study, and he contributed to conceive the study design, to conduce the statistical analysis and to redact the manuscript. All authors read and approved the final manuscript.

\section{Competing interests}

The authors declare that they have no competing interests.

Received: 22 March 2011 Accepted: 5 August 2011

Published: 5 August 2011

\section{References}

1. Rutter M: Resilience in the face of adversity: protective factors and resistance to psychiatric disorders. Br J Psych 1985, 147:598-611.

2. Norris FH, Stvens SP, Pfefferbaum B, Wyche KF, Pfefferbaum RL: Community resilience as a metaphor, theory, set of capacities, and strategy for disaster readiness. Am J Community Psychol 2008, 41:127-150.

3. Ahern NR, Kiehl EM, Lou Sole M, Byers J: A review of instruments measuring resilience. Issues in Comprehensive Pediatric Nursing 2006, 29:103-25.

4. Windle G, Bennett KM, Noye J: A methodological review of resilience measurement scale. Health and Quality of Life Outcomes 2011, 9:8.

5. Connor KM, Davidson JRT: Development of a new resilience scale: The Connor-Davidson Resilience Scale (CD-RISC). Depression and Anxiety 2003, 18:76-82.

6. Campbell-Sills L, Stein MB: Psychometric analysis and refinement of the Connor-Davidson Resilience Scale (CD-RISC): validation of a 10-item measure of resilience. Journal of Traumatic Stress 2007, 20:1019-28.

7. Singh K, Yu XN: Psychometric evaluation of the Connor-Davidson Resilience Scale (CD-RISC) in a sample of Indian students. J Psychology 2010, 1:23-30.

8. Wang $L$, Shi Z, Zhang $Y$, Zhang Z: Psychometric properties of the 10-item Connor-Davidson Resilience Scale in Chinese earthquake victims. Psychiatry and Clinical Neurosciences 2010, 64:499-504.

9. Bobes J, Bascarán MT, García-Portilla MP, Bousoño M, Sáiz PA, Wallance DH: Banco de instrumentos básicos de psiquiatría clínica. Barcelona: Psiquiatría ED; 2001.

10. Alonso J, Regidor E, Barrio G, Prieto L, Rodríguez C, de la Fuente L: Valores poblacionales de referencia de la versión española del Cuestionario de Salud SF-36. Med Clin Barc 1998, 111:410-416.

11. Buysse DJ, Reynolds CF, Monk TJ, Berman SR, Kupfer DJ: The Pittsburgh Sleep Quality Index: a new instrument for psychiatric practice and research. Psychiatric Research 1989, 28:193-213.

12. Macías JA, Royuela A: La versión española del índice de calidad de sueño de Pittsburgh. Informaciones Psiquiátricas 1996, 146:465-472.

13. Campbell-Sills L, Forde DR, Stein MB: Demographic and childhood environmental predictors of resilience in a community sample. Journal of Psychiatric Research 2009, 43:1007-1012.

14. Hu L, Bentler PM: Cutoff criteria for fit indexes in covariance structure analysis: Conventional criteria versus new alternatives. Structural Equation Modeling 1999, 6:1-55.

15. Connor KM, Zhang W: Recent advances in the understanding and treatment of anxiety disorders. Resilience: determinants, measurement, and treatment responsiveness. CNS Spectr 2006, 11(Suppl 12):5-12.

16. Carli V, Roy A, Bevilacqua L, Maggi S, Cesaro C, Sarchiapone M: Insomia and suicidal behaviour in prisioners. Psychiatry research 2011, 185:141-144.

17. Cohen J: Statistical power analysis for the behavioral sciences. New York, Academic Press: 21988

18. Byrne BM: Structural equation modeling with AMOS: Basic concepts, applications and Programming. New York, Taylor and Francis Group; 2 2010.

19. Yu XN, Lau JTF, Mak WWS, Zhang J, Lui WWS, Zhang J: Factor structure and psychometric properties of the Connor-Davidson Resilience Scale among Chinese adolescents. Comprehensive Psychiatry 2011, 52:218-224.

20. Lamond AJ, Depp CA, Allison M, Langer R, Reichstadt J, Moore DJ, Golshan S, Ganiats TG, Jeste DDV: Measurement and predictors of resilience among community-dwelling older women. Journal of Psychiatric Research 2009, 43:148-154.

21. Karaırmak Ö: Establishing the psychometric qualities of the ConnorDavidson Resilience Scale (CD-RISC) using exploratory and confirmatory factor analysis in a trauma survivor sample. Psychiatry Res 2010, 179:350-356.

22. Burns RA, Anstey KJ: The Connor-Davidson Resilience Scale (CD-RISC): testing the invariance of a uni-dimensional resilience measure that is independent of positive and negative affect. Personality and Individual Differences 2010, 48:527-531.

23. Taylor DJ, Mallory LJ, Lichstein KL, Durrence HH, Riedel BW, Bush AJ: Comorbidity of chronic insomnia with medical problems. Sleep 2007, 30:213-218.

24. Rew L, Taylor-Seehafer M, Thomas NY, Yockey RD: Correlates of resilience in homeless adolescents. J Nurs Scholarsh 2001, 33:33-40. 
25. Wills TA, Sandy JM, Shinar O, Yaeger A: Contributions of positive and negative affect to adolescents substance use: test of a biodimensional model in a longitudinal study. Psychol Addict Behav 1999, 13:327-338.

26. Stein MB, Campbell-Sills L, Gelernter J: Genetic variation in 5 HTTLPR is associated with emotional resilience. Am J Med Genet B Neuropsychiatr Genet 2009, 150B:900-906.

doi:10.1186/1477-7525-9-63

Cite this article as: Notario-Pacheco et al:: Reliability and validity of the Spanish version of the 10-item Connor-Davidson Resilience Scale (10item (D-RISC) in young adults. Health and Quality of Life Outcomes 2011 9:63.

Submit your next manuscript to BioMed Central and take full advantage of:

- Convenient online submission

- Thorough peer review

- No space constraints or color figure charges

- Immediate publication on acceptance

- Inclusion in PubMed, CAS, Scopus and Google Scholar

- Research which is freely available for redistribution

Submit your manuscript at www.biomedcentral.com/submit 